\title{
English for Medical Purposes Should Not Be Silent: Promoting Intercultural Communication of EMP in China
}

\author{
Yangyang $\mathrm{Lu}^{1, *}$ \\ ${ }^{1}$ School of Foreign Languages, Nanjing Institute of Tourism and Hospitality, Nanjing, Jiangsu, China \\ *Correspondence: 101 Village Green Lane, Apt A, Carmel, IN., USA. Tel: 1-463-206-9966. E-mail: \\ yangyang120884@gmail.com
}

Received: March 23, 2020

Accepted: April 2, 2020 Online Published: July 15, 2020

doi:10.5430/ijelt.v7n2p16

URL: https://doi.org/10.5430/ijelt.v7n2p16

\begin{abstract}
With the rapid growth of academic cooperation of medical science between China and the world, there has been an increasing demand of intercultural communication in English for medical purposes (EMP) in China. For a long time, people in China have attached importance to reading and writing in EMP while neglecting the listening and speaking ability of medical students. The aim of this paper is to demonstrate the situation of intercultural communication between Chinese doctors and foreign patients and explain the significance of verbal communication in EMP. Based on data collected from discourse cases in Chinese medical settings, this paper demonstrates that EMP in China should pay more attention to the three critical elements: medical jargon, contextualized language, and cultural difference, and analyzes the significance of three elements through qualitative research. This paper also explores underlying reasons of intercultural communication failure between Chinese doctors and foreign patients, and helps to develop the idea that EMP teaching in China should not be silent.
\end{abstract}

Keywords: intercultural communication, English for medical purposes, medical jargon, contextualized language, cultural difference

\section{Introduction}

\subsection{Research Purpose}

In 2010, the registered number of foreigners living in China in the Sixth National Population Census was around 600,000 . At the same time, the number of foreigners who go to China for short-term business, academic studies and tourism activities grows rapidly every year. Thus, the number of foreign patients visiting medical institutions in China has increased significantly, and foreign-related medical activities are frequent. However, Chinese medical staff faces many problems in the process of oral communication with patients from different countries for the lack of training in intercultural communication skills in English for medical purposes.

In the process of communicating with foreign patients, the most important part is to be able to understand the conversation and exchange ideas. Yet, low oral literacy of English for medical purposes affects the smooth transaction of intercultural communication in medical situations. Many foreign patients in China have pointed out that Chinese medical doctors have made language errors in intercultural communication that patients cannot comprehend. Without the knowledge of intercultural communication in medical settings, medical workers would not be able to correctly interpret the information conveyed by foreign patients and make the right medical judgment and treatment. Thus, this paper first discusses the research background of intercultural communication of English for specific purposes in China, and then reviews the literature of EMP and intercultural communication in medical situations. The paper aims to promote intercultural communication of EMP in China supported by the theories of Roter's Interaction Analysis System (RIAS) (2011) and Whelan's Cross-Cultural aspects of challenges faced by international medical graduates (2006). Finally, these theories are applied to the analyses of different cases of intercultural communication of EMP in China.

\subsection{Research Background}

The study of EMP in China began in the 1960s. In 1999, the Ministry of Education launched College English 
Teaching Guidelines (Revision) which established the status of "English for Specific Purposes" in the more general field of English teaching. The research and teaching of EMP has also begun to flourish. Medical students are required to read medical literature, write academic essay in English, communicate with foreign patients verbally, and exchange ideas with foreign colleagues. For a long time, there has been a widespread tendency in EMP teaching in China that attaches importance to enabling students to read and write while neglecting the listening and speaking components of EMP. Moreover, cultural differences, communication styles, and politeness strategies with foreign patients in intercultural communication have not been given enough attention in EMP teaching. Thus, the communicative competence of Chinese doctors is unsatisfactory, rendering complicated internationalization of medical activities impossible.

The medical staff should not only have fluent language expression ability, but also understand their foreign patients' pragmatic habits, their unique culture, and, consequently, eliminate or reduce barriers to medical treatment caused by different language and cultural backgrounds. This allows them to have effective intercultural communication in medical situations. Therefore, EMP teaching for medical students should cultivate their intercultural communicative competence in medical situations in order to serve foreign patients more professionally.

\section{Literature Review}

\subsection{English for Medical Purposes}

The term "English for Medical Purposes" refers to "the teaching of English for doctors, nurses and other personnel in the medical professions" (Maher, 1986). It is generally regarded as a branch of English for Specific Purposes (ESP). EMP is the term that applied linguists prefer to use, while "communication skills in medicine" is the term that medical educators would use. There has been significant research on these two terms in the past years. Gotti \& Salager (2006) divided EMP into two parts: the first targets medical discourse in its spoken dimension; the second contains various analyses of written texts. Ainsworth-Vaughn (2001) emphasizes the significance in doctor-patient communication. Fleischman's study (2001) examines the discourse analysis of medical English while Shi (2009) focuses on the theory and practice of English for medical purposes. In general, EMP is to meet the communication needs of medical staff and medical students who need to use English. "English" is the medium of communication, and medical information is the content of communication. "Medical" and "English" should not be simply added together but should be organically integrated (Ruan \& Tao, 2007). Kramsch (2005) points out that the content and form of the language itself is decided by the culture in which it is used. If we do not understand the cultural background, we cannot use the language correctly. Therefore, culture should be the core of language teaching, and the goal of EMP should focus on the intercultural communication ability in medical situations.

\subsection{Intercultural Communication in Medical Settings}

Intercultural communication is a discipline that conducts the study of communication across different cultures and social groups, or discusses how culture affects communication. International communication in medical situations refers to the communication between medical staff and patients from different cultures in hospitals. Korsh \& Negrete (1972) have studied the communication during diagnosis and medical examination between doctors and patients and point out the insufficiency of information provided by doctors. Heath (1986) has found that patients don't respond to doctor's diagnostic information during doctor-patient communication. Bensing (1991) believes that successful communication should be patient-centered, should directly encourage the cooperation of patients, and should improve the effect of treatment. Roter (2011) and colleagues have proposed a system called "The Roter interaction analysis system (RIAS)," which conceptualizes the oral literacy demand of health care communication in terms of four elements: (1) medical jargon; (2) general language complexity; (3) contextualized language, and (4) structural characteristics of dialogue. Among them, medical jargon and contextualized language have positive significance in terms of intercultural communication in Chinese medical situations.

In addition, cross-cultural aspects of the challenges faced by international medical graduates (IMGs), including aspects of general professionalization, are the subject of a special issue of Academic Medicine (Whelan, 2006). As Whelan (2006) points out, even the most "fluent" IMG may find certain topics "baffling". These topics in Chinese medical situations of intercultural communication may include the differences in medical value, medical custom, medical system and medical service among various countries. Thus, Cultural difference is another important element that would affect the intercultural communication between Chinese medical graduates and foreign patients. 


\section{Method}

\subsection{Data Collection}

Data were collected from examples of the conversation between Chinese doctors and foreign patients in some Chinese works and dissertations. For instance, Y. P. Peng (2012) explored Chinese doctors' failure of understanding medical terminology and cultural difference in her doctor's dissertation "A Study on Intercultural Communication Competence in Healthcare Context." Haiyan Zhang (2003) explained the relation between Chinese doctors and foreign patients and gave examples of Chinese doctors' misunderstanding of EMP contextualized language in his dissertation "Sociolinguistic Study of Doctor-patient Relations." J. H. Ma and Q. Wang (2004) analyzed speech characteristics in medical activities and presented typical examples in Medicine and Philosophy. G. P. Wang (2006) viewed the similarities and differences between Chinese medical graduates and English patients from the politeness criterion and offered examples of cultural difference. J. Y. Wang (2010) also probed into the cultural functions of medical Language.

\subsection{Data Analysis}

The analysis of the data was based on some earlier studies that discussed two elements of the Roter (2011) interaction analysis system: medical jargon and contextualized language and another element of cultural difference of international medical graduates mentioned by Whelan (2006). These elements would affect the intercultural communication between Chinese doctors and foreign patients. Data were analyzed by qualitative method. The focus of analysis was on exploring the importance of three elements in cross-cultural communication between Chinese medical graduates and foreign patients, gaining an understanding of underlying reasons of intercultural communication failure between Chinese doctors and foreign patients, and helping to develop the idea that EMP teaching in China should not be silent.

\section{Results and Discussion}

\subsection{Medical Terminology}

Medical terminology between doctors and patients is the specific application of human language in medical settings that are often used by doctors when they use English for their medical activities. As early as the 1960s, researchers indicated that medical term was widely used in daily medical activities and were related to patient confusion, and the situation has not changed during the past 60 years. In China, Zhang (2003) conducted a discourse analysis and found that the use of medical jargon hindered the effective communication between Chinese doctors and foreign patients. Hahn (1995) believes that the simplicity of information provided by doctors in doctor-patient communication and the popularity of language are positive for effective communication. Obviously, it is important for the doctor to use medical terminology appropriately; otherwise it will cause communication barriers in the process of communicating with patients. It is also essential for medical students to master how to use medical terms in English for medical purposes correctly. However, the appropriate use of medical terminology in EMP that Chinese medical students' study is not sufficient. Here is an example (Peng, 2012):

Example 1:

D: What is your trouble, Sir?

$\mathrm{P}$ : I believe there is something wrong with my heart.

D: Did you have any heart disease before?

P: My doctor in America told me before I had a murmur.

D: Murmur? Murmur has no relation with your heart.

The idiom "murmur" used in ordinary English means "whisper" while it should be understood as "heart murmur" in medical context. In this case, the patient told the doctor about his medical history of being diagnosed with heart murmur, but the doctor understood it as "whispering" because he did not understand how the patient's whispering had anything to do with the patient's disease. Chinese doctors lack knowledge in medical terminology; they misunderstand the meaning of "murmur," which leads to the communication barriers between Chinese doctors and foreign patients.

There are a lot of medical jargons that are composed of roots and affixes derived from Greek and Latin. The roots and affixes in medical terminology can be divided into two categories. One is specific to medical term, such as "-ase" (enzyme), as in "ketolase" and "thioglucosidase." The other category can be used in both everyday English 
and medical terminology with different meanings, such as "-ism" which means "poisoning, disease, morbidity" in medical terminology but means "doctrine, behavior, state" in everyday usage. In medical jargon, the communication between Chinese doctors and foreign patients mainly occurs in the second type of roots and suffixes. At the same time, Chinese doctors like to use their own word formation methods to create medical jargon and generate errors in the process of communication.

Example 2:

D: What's wrong with you, Madam?

P: I suffer from a pain in my waist.

D: When did your waist pain start?

P: Yesterday. We often use Lumbago instead of waist pain.

D: I am so sorry about that. (Peng, 2012)

The description of "pain" in medical jargon requires the use of different words. "-ache" is to express toothache, backache, stomachache, etc.; "-dynia" is to express acrodynia, arthrodynia, etc. However, lumbago is a special word to express this meaning. In this case, the doctor took the combination of the waist and the pain and invented the "waist pain." The patient realized that the doctor might not know the medical jargon of the word "lumbago" and told the doctor euphemistically.

Undoubtedly, Chinese medical students are proficient in their medical knowledge and medical practice, but it is better for them to apply medical jargon skillfully and employ the profound and complicated medical jargon appropriately in their future career. Only in this way can they have good intercultural communication with foreign patients.

\subsection{Contextualized Language}

Contextualized language conveys concrete ideas or plain use of language to describe an event or a situation to another person. Dexter (1998) and Farmer (2006) believe that patients are more likely to use and understand language that is concrete and grounded in what is directly seen and experienced in EMP.

Here is an example of contextualized language in EMP (Zhang, 2003). In the intercultural communication of the medical situation between Chinese doctors and foreign patients, the discourse content of the two parties will inevitably involve the body parts. For the body's privacy and idiomatic language, foreign patients usually use expressions in contextualized language to avoid communication embarrassment between the two parties.

Example 3:

D: What's wrong with you?

P: My period is only for half a day and I get terrible headache.

D: Do you have pains in your period?

P: A little.

D: How often do you have your period?

P: It varies. Every three or four weeks.

D: It lasts for how many days?

P: Four, four days.

For "menstruation," foreign patients do not use the expression "menstruation" in EMP, but use the word "period," which is a euphemistic statement in the contextualized language of EMP. When talking about the patient's "menstrual period," the doctor did not use the expression in EMP but used "It lasts for how many days?" When talking about whether a patient has "menstrual pain," he used a more contextualized way of "Do you have pains in your period?" In this case, because Chinese doctors understand the contextualized expression of patients, they can correctly understand the meaning of patients' words and guess the intention of words. In this way, Chinese doctors communicate with foreign patients appropriately and effectively.

However, this successful case in the contextualized language of EMP are rare in China. Many Chinese medical students lack the knowledge of contextualized language. They often use the same medical terms in all medical settings, which may cause barriers in intercultural communication between Chinese doctors and foreign patients. 
Example 4:

D: Do you suffer from Constipation?

P: Yes, I haven't gone for four days.

D: What?

P: I mean I haven't had a bowel movement for four days.

D: What is a bowel movement?

P: Oh, (laughing), a bowel movement means defecation.

D: Oh, I see. Now I will give you the prescription (Ma \& Wang, 2004).

In this case, a Chinese doctor used the expression of "Do you suffer from Constipation?" when foreign patients were constipated. "Constipation" is an English medical vocabulary with no error. However, in the actual communication process, people often use a contextualized expression. Therefore, when the foreign patient answered the doctor's question, the expression "I haven't gone for four days." was adopted. "Gone" means "gone to the bathroom." The doctor was unfamiliar with this expression and did not understand the meaning of the patient, so the patient used the expression "I haven't had a bowel movement for four days." The doctor could not guess the meaning of the contextualized language again. After the patient explained the meaning of "a bowel movement," the Chinese doctor understood the meaning of the phrase and gave the patient the prescription. Finally, the communication was resumed.

Obviously, the plain use of contextualized language that is directly seen and experienced avoids the embarrassment caused by the communication between doctors and patients. It is essential for Chinese doctors to get familiar with the contextualized language in their daily communication with foreign patients.

\subsection{Cultural Difference}

Zhao (1999) has discovered that there are many differences between foreign patients and Chinese doctors in language, values, medical concepts, medical systems, customs, taboos, religious beliefs, eating habits, etc. which may cause oral communication barriers, failures, and even conflicts. EMP is based on thinking, language, and culture and is influenced by historical, social environments and even religious beliefs. Thus, cultural difference affects people's use of EMP.

Different cultures have different titles in medical settings, and even the same title sometimes has different implications in different cultures. In the intercultural communication of medical situations, the appropriate use of title can promote a good relationship between doctors and patients and establish a good foundation for further communication between doctors and patients.

Example 5:

D: I'll give you a prescription for some tablets to ease the pain.

P: I've been given so much that I simply don't know what to do with it all.

D: Well, don't worry, old Madam. I'll tell you how to use it in detail.

P: Doctor, I'm not old! I'll read the instruction by myself. (Wang, 2006)

Like this case, many Chinese medical students do not understand that the word "old" is a taboo in the western culture, which causes the conflict between doctors and patients. For the word of "old," Chinese and Western cultures have completely different understandings. Chinese culture advocates the traditional virtues of respecting the old and believes that the elderly is experienced and intelligent. In the Chinese culture, "old" is a symbol of qualification, dignity, and authority. In Western culture, "old" is a very impolite expression that means weak and useless by society, and youth is full of vigor and creativity. Westerners have a strong self-esteem of "not accepting the old." Thus, the patient believed that the doctor was not respectful to her and refused the help of the doctor. It is undoubtedly significant for Chinese medical students to study different cultures in EMP learning.

In addition, the human rights beliefs in Europe and America are prominently reflected in the concern and respect for the sick, and sickness is a topic of taboo. People with disabilities are usually referred to in a euphemistic way, such as a "special student" instead of a "disabled student"; the "handicapped" instead of the "crippled." Here is an example (Wang, 2010).

Example 6:

D: Can you hear me? 
P: Not clear.

D: Ok, I'll check your ears.

$\mathrm{P}$ : Anything wrong?

D: No wound in your ear? Were you deaf before?

P: What, deaf? Doctor, I had nothing wrong with my hearing before; I'm not deaf; don't use this word anymore. Please respect me.

In the above doctor-patient dialogue, the Chinese doctor misunderstood the word "deaf," which foreigners believe to have a discriminatory meaning, which led to intercultural communication barriers. In the West, doctors often use the expression of "hearing impairment" instead of "deaf." Chinese doctors are not familiar with the culture in the West, which makes communication unpleasant.

Cultural differences sometimes lead to the different meanings of phrases in English and Chinese when expressing the same target.

Example 7:

P: Doctor, I always feel sick.

D: Has it happened for a short period or a long time?

P: It appears only a short period.

D: When did it start?

P: The day before yesterday.

D: Do you have morning sickness?

P: Doctor, only women have morning sickness when they are pregnant.

D: I'm sorry, what I mean is do you feel sick in the morning?

P: No, usually in the afternoon, about 5 o'clock, before supper. (Peng, 2012)

In this case, the doctor translated the morning vomiting phenomenon as "morning sickness," but in English "morning sickness" has its specific meaning, which refers to "pregnant morning sickness." This brings discomfort to the patient. Sometimes, the medical English expression has a strong cultural allusion and develops into the vocabulary of daily medical encounter, such as cesarean birth. These medical words derived from the Bible, Greek or Roman mythology and cannot be translated superficially; otherwise they will be confusing, e.g., cyclopia, Achilles tendon, Hippocratic sound, Job's syndrome, etc.

Diverse cultural and historical backgrounds have led to the differences in medical values, medical customs, and medical systems among various countries and nations (Li \& Yang, 2009). Chinese medical students should focus on cultural difference in order to avoid the communication barriers between Chinese doctors and foreign patients.

\section{Conclusion}

As it has been demonstrated in this paper, intercultural communication plays a significant role for the future of EMP in China because verbal communication between Chinese doctors and foreign patients has been neglected for many years. Cultural differences and communication styles have not been given enough attention in EMP teaching. Consequently, this paper has proposed a system that conceptualizes the oral literacy demand of healthcare communication in China in terms of three elements: medical terminology; contextualized language, and cultural difference. Firstly, it is significant for the doctor to use medical terminology appropriately in EMP; otherwise it will cause communication barriers in the process of communicating with patients. Secondly, contextualized language in EMP facilitates the plain use of medical English to describe the situation of a patient that is directly seen and experienced. Thirdly, cultural differences affect people's use of EMP, especially in thinking, language, and culture. Thus, it is essential for Chinese doctors and medical students to master how to execute appropriate intercultural communication in English for medical purposes. The analyses of medical terminology, contextualized language, and cultural differences in intercultural communication of EMP will be very helpful for Chinese medical discourse analysis, especially the intercultural communication between Chinese doctors and foreign patients. 


\section{References}

Ainsworth-Vaughn, N. (2001). The discourse of medical encounters. In D. Schiffrin, D. Tannen, \& H. Hamilton (Eds.), The Handbook of Discourse Analysis, 453-469. Malden, MA: Blackwell. https://doi.org/10.1002/9780470753460.ch24

Bensing, J. (1991). Doctor-patient communication and the quality of care. Social Science and Medicine, 32(11), 1301-1310. https://doi.org/10.1016/0277-9536(91)90047-G

Dexter, E. R., LeVine, S. E., \& Velasco, P. M. (1998). Maternal schooling and health-related language and literacy skills in rural Mexico. Comp Educ Rev, 42, 139-162. https://doi.org/10.1086/447493

Farmer, S. A., Roter, D. L., \& Higgenson, I. J. (2006). Chest pain: Communication of symptoms and history in a London emergency department. Patient Educ Couns, 63, 138-144. https://doi.org/10.1016/j.pec.2005.09.009

Fleischman, S. (2001). Language and medicine. In D. Schiffrin, D. Tannen, \& H. Hamilton (Eds.), The Handbook of Discourse Analysis (pp. 470-502). Malden, MA: Blackwell.

Gotti, M., \& Salager-Meyer, F. (Eds.). (2006). Adcances in medical discourse analysis: Oral and written contexts. Bern: Peter Lang. https://doi.org/10.3726/978-3-0351-0396-0

Hahn, R. A. (1995). Sickness and Healing: An anthropological perspective. New Haven: Yale University Press.

Heath, C. (1986). Body Movement and Speech in Medical Interaction. Cambridge: Cambridge University Press. https://doi.org/10.1017/CBO9780511628221

Korsh, B. M., \& Negrete,V. F. (1972). Doctor-patient communication. Scientific American, 66-74. https://doi.org/10.1038/scientificamerican0872-66

Kramsch, C. (1998b). Language and Culture. Oxford: Oxford University Press.

Li, D., \& Yang Q. (2009). Chinese and Western Cultural Differences: Medical System, Medical Ethics and Medical Insurance. Northwest Medical Education, 8.

Ma, J. H., \& Wang, Q. (2004). Analysis of Speech Characteristics in Medical Activities. Medicine and Philosophy, 18(1), 49-65. https://doi.org/10.1016/S0885-2308(03)00031-7

Maher, J. (1986). English for Medical Purposes. Cambridge: Cambridge University Press. https://doi.org/10.1017/S0261444800012003

Peng, Y. P. (2012). A Study on Intercultural Communication Competence in Healthcare Context. Doctor's Dissertation of Shanghai Foreign Languages University.

Ruan, J. Z., \& Tao, Z. J. (2007). Business English Grounds and Curriculum Design Principles. Journal of Zhejiang University of Technology, 4, 414-419.

Roter, D. L. (2011). Oral literacy demand on health care communication: challenges and solutions. Nursing Outlook, 59(2), 79-84. https://doi.org/10.1016/j.outlook.2010.11.005

Roter, D. L., Erby, L., Larson, S., \& Elington, L. (2009). Oral literacy demand of prenatal genetic counseling dialogue: predictors of learning. Patient Education and Counseling, 75(3), 392-397. https://doi.org/10.1016/j.pec.2009.01.005

Shi, L. (2009). English for medical purposes. In D. Belcher (Ed.), English for Specific Purposes in Theory and Practice (pp. 205-228). Ann Arbor: University of Michigan Press.

Whelan, G. (2006). Commentary: Coming to America: The integration of international medical graduates into the American medical culture. Academic Medicine, https://doi.org/10.1097/00001888-200602000-00017

Wang, G. P. (2006). Viewing the similarities and differences between Chinese and English from the politeness criterion. Journal of Anhui University of Technology, 1, 113-115.

Wang, J. Y. (2010). A probe into the cultural functions of medical Language. Medicine and Society, 1, 67-69.

Zhang, H. (2003). Sociolinguistic Study of Doctor-patient Relations. Master's Degree Thesis of Wuhan University of Technology.

Zhao, B. (1999). Asymmetry and mitigation in Chinese medical interviews. Health Communication, 11(3), 209-214. https://doi.org/10.1207/S15327027HC110303 


\section{Copyrights}

Copyright for this article is retained by the author(s), with first publication rights granted to the journal.

This is an open-access article distributed under the terms and conditions of the Creative Commons Attribution license (http://creativecommons.org/licenses/by/4.0/). 